\title{
A Reconsideration of the Physical Laws for Transforming Environmental Resources in Post-Keynesian Production Theory
}

\author{
Paul P. Christensen \\ and \\ Richard G. Fritz* \\ INTRODUCTION
}

Despite considerable progress in mathematical technique and empirical rigor, economic science does not yet possess a consistent and logically acceptable theory of production, value and distribution. The post-Keynesian debate over capital theory has demonstrated the rather special assumptions on which neoclassical theory has been constructed. Recent work in environmental economics has focused on the absence of a satisfactory formulation of the physical-technical requirements of production processes in neoclassical theory. Each approach-the post-Keynesian and the environmental-attempts to recast economic theory consistent with its particular understanding of the requirements for theoretical adequacy; but each proceeds without the insights of the other. Post-Keynesian theory lacks a full specification of environmental resources in its production equations. The environmental approach lacks a framework for the integration of its insights about the material basis of production with the structure of economic activity. This paper synthesizes the contribution of the environmental economists within a post-Keynesian framework.

A number of post-Keynesian writers suggest a return to classical models for alternatives to neoclassical theory (Harcourt, 1976; Laibman and Nell, 1977). Although there has been important work on the links between distribution and accumulation (Kaldor, 1957; Pasinetti, 1962), little has been done exploring the classical approach to a theory of production beyond Sraffa's initial reformulation of Ricardo (Sraffa, 1960). Sraffa's construction of an approach to production based on the transformation of heterogenous commodities into commodities unsettled the foundations of orthodox theory. This has not, however, been elaborated beyond a critique to provide the necessary framework for a complete theory of production, value and distribution. What is

†The authors greatfully acknowledge the contributions of Thomas von Foerster of Physics Today in the development of the ideas of this paper.

*Visiting Assistant Professor and Assistant Professor, University of Central Florida, Orlando, Florida. 
missing in current work is the emphasis which classical theorists placed not only on the heterogeneity of produced means of production but on production as a flow of nature into commodities.

The marginalists switched the focus of economic analysis from the production and accumulation of material wealth to the problem of the optimal allocation, through exchange, of an initial endowment of resources. Production theory was altered from a conception of the transformation of nature into commodities via labor to a preconceived model based on the marginal contribution of substitutable resource stocks. When production theory is focused on the optimal "allocation" of stocks of resources, the nature of production as a flow of matter and energy is disguised and production as a process is delegated to a subordinate role. Post-Keynesian work has returned production analysis to the center of economic theory but has neglected the explicit consideration of the flows of environmental resources which are the necessary physical basis of commodity production.

Environmental economists have formulated another attack on the structure of neoclassical theory. They have pointed out that economic activity neither creates nor destroys matter but merely transforms it (Daly, 1968; Victor, 1972; Herfindahl and Kneese, 1974; and Ayres, 1978). Production theory in economics cannot violate the laws of the conservation of matter and energy. The modern notion of material balances recognizes that all materials extracted from the natural environment and used in the economic system continue to exist in some form. Materials balance is an accounting for the source, use and disposition of the agents transformed in the process of economic activity. The focus of the environmental paradigm has been on the physical reality of material transformations. While this approach has attempted to formulate a production analysis consistent with the laws of thermodynamics, the analysis has been confined to considerations of policy to correct market flaws. It has not been extended to a reconsideration of the neoclassical theory of value and distribution.

The first stage of the paper will discuss the post-Keynesian formulation. This will include a general analysis of the Sraffa-Pasinetti model. The framework of this analysis will be explored with later reference to its value in a synthesized model. The second phase of the paper discusses the material-energy balances approach of the environmental models. This model requires economic analysis to consistently fit the physical laws. The physical constraints of the environmental economists will be combined with the postKeynesian approach. The final part of the paper will present the implications of the synthesized model.

\section{POST-KEYNESIAN STRUCTURE}

Produced commodities must be analyzed as a flow of the accumulating "means of production" and exogenously given natural resources. The modern form of double-entry analysis used by Leontief and Sraffa provides a technical 
framework which expresses insights developed by the classical economists. Production activity is described in two systems: a system of physical quantities and a system of prices. In classical theory, economic activity begins in production and prices are developed in relation to the production system. We consider, therefore, the physical aspects of production first.

Let the total quantities $\mathrm{Q}_{1}, \mathrm{Q}_{2}, \ldots ., \mathrm{Q}_{\mathrm{n}}$ represent the physical inputs that are transformed in order to obtain the given set of final commodities $\mathrm{Y}_{1}$, $\mathrm{Y}_{2}$, . . . , $\mathrm{Y}_{\mathrm{n}}$. From the basic "open" Leontief system, production activity may be described by the equation set below:

$$
\begin{array}{cc}
\mathrm{a}_{11} \mathrm{Q}_{1}+\mathrm{a}_{12} \mathrm{Q}_{2}+\ldots & +\mathrm{a}_{1 \mathrm{n}} \mathrm{Q}_{\mathrm{n}}+\mathrm{Y}_{1}=\mathrm{Q}_{1} \\
\mathrm{a}_{21} \mathrm{Q}_{1}+\mathrm{a}_{22} \mathrm{Q}_{2}+\ldots & +\mathrm{a}_{2 \mathrm{n}} \mathrm{Q}_{\mathrm{n}}+\mathrm{Y}_{2}=\mathrm{Q}_{2} \\
\cdot & \cdot \\
\cdot & \cdot \\
\cdot & \cdot \\
\mathrm{a}_{\mathrm{n} 1} \mathrm{Q}_{1}+\mathrm{a}_{\mathrm{n} 2} \mathrm{Q}_{2}+\ldots & +\mathrm{a}_{\mathrm{n} n} \mathrm{Q}_{\mathrm{n}}+\mathrm{Y}_{\mathrm{n}}=\mathrm{Q}_{\mathrm{n}}
\end{array}
$$

The quantities of $Y$ will differ from one commodity to another and they must all be non-negative. The $a_{\mathrm{ij}}$ 's are the industry coefficients in the technological production matrix $A$. System (1) may be compactly written as

$$
\mathrm{AQ}+\mathrm{Y}=\mathrm{Q}
$$

The problem is to find the total quantities, $Q_{\mathrm{i}}$ 's, which must be produced in order to obtain a given set of physical rates of surplus, $R_{1}, R_{2}, \ldots ., R_{n}$, where $R$ is defined as the ratio

$$
\mathrm{R}_{\mathrm{i}}=\frac{\mathrm{Y}_{\mathrm{i}}}{\mathrm{Q}_{\mathrm{i}}-\mathrm{Y}_{\mathrm{i}}}
$$

Now equation system (2) may be rewritten as:

$$
(1+\mathrm{R}) \mathrm{AQ}=\mathrm{Q}
$$

A necessary condition for nonzero solutions to the matrix system (3) is that the determinant of the coefficient matrix be zero. This implies that the physical rates of surplus cannot all be taken as given. At least one must be able to satisfy the necessary condition above. The solution to system (3) may be expressed as

$$
\left([1+R]^{-1} I-A\right) Q=0
$$

Classical theorists from Quesnay and Ricardo to Sraffa have presumed the productivity of an economic system, i.e. the ability of the system to produce output above the input requirements (replacement of the means of production used up and subsistence) of the system. However, considered as a physical system, matter and energy are being transformed into new forms. A physical description of these transformations as opposed to an "economic" description 
requires consistency with the principles of the conservation of matter and energy. In classical economic theory, a commodity surplus is a prerequisite for a "productive" economy. However, as a description of an open economy," classical theory is incomplete because it does not explain the physical source of the surplus. We shall return to system (4) later to consider the requirements imposed on the model by the laws of physics.

The second phase of the Sraffa model is the price system. Prices are constructed as the valuation of the materials (commodities) required to reproduce the system over time. Before price equations can be written, the way in which the economic system distributes physical surplus must be specified. In a capitalist economy, surplus is distributed according to the value of the means of production advanced. Separating labor requirements, we can write price equations where prices cover means of production advanced (materials throughput and capital services), wages and "normal" profit earned on capital advanced. It is defined as:

$$
\begin{aligned}
& \left(a_{11} p_{1}+a_{21} p_{2}+\ldots+a_{n, 1} p_{n}\right)(1+\pi)+a_{11} w=p_{1} \\
& \left(\mathrm{a}_{12} \mathrm{p}_{1}+\mathrm{a}_{22} \mathrm{p}_{2}+\ldots+\mathrm{a}_{\mathrm{n}, 2} \mathrm{p}_{\mathrm{n}}\right)(1+\pi)+\mathrm{a}_{12} \mathrm{w}=\mathrm{p}_{2} \\
& \left(a_{1, n} p_{1}+a_{2, n} p_{2}+\ldots+a_{n, n} p_{n}\right)(1+\pi)+a_{1, n} w=p_{n}
\end{aligned}
$$

The prices of the economic system's resource inputs and commodities are defined by the row vector $p$. The value added is divided between wages and profits, with both measured as scalars ( $w$ and $\pi$, respectively). For convenience, it is assumed that labor is uniform in quality and wage and profit rates are the same for each sector. In matrix notation, system (5) may be written as:

$$
\mathrm{pA}(1+\pi)+\mathrm{a}_{1} \mathrm{w}=\mathrm{p}
$$

The system contains $n$ equations and $n+2$ unknowns (n prices, w, and $\pi$ ). One price can be set equal to unity (we are interested in relative prices), but this leaves one more unknown than there are equations. Alternative solutions have been suggested: a classical solution to this extra degree of freedom took wages as determined exogenously by subsistence requirements; Marx took the proportion of profits to wages as fixed and determined by the rate of exploitation; neo-Keynesians regard distribution as constrained by the rate of accumulation. In any case, a solution to equation system (5) (and 6) cannot be entirely endogenously determined.

A necessary condition for a solution with economic meaning is that the determinant of the matrix of coefficients be zero. The maximum eigenvalue, $\left(\frac{1}{1+\pi_{m}}\right)$, will yield an eigenvector whose prices are not negative. So let $\pi$ be the rate of profit which is associated with $\left(\frac{1}{1+\pi_{\mathrm{m}}}\right) .^{2}$ We may obtain the deter- 
minant, with non-negative solutions for all relative prices:

$$
\begin{gathered}
\text { let } \pi=\bar{\pi}, \text { with } 0<\bar{\pi}<\pi \\
\mathrm{p}=\left(\frac{1}{1+\pi}\right) \mathrm{a}_{1}\left[\left(\frac{1}{1+\pi}\right) \mathrm{I}-\mathrm{A}\right]{ }^{-1} \mathrm{w} \\
\mathrm{p}=\mathrm{a}_{1}[\mathrm{I}-(1+\bar{\pi}) \mathrm{A}]{ }^{-1} \mathrm{w}
\end{gathered}
$$

or

Classical economists conducted a persistent search for a standard of value more basic than market prices and existing distribution relations. Ricardo and Marx regarded labor as the limiting factor of production and the basic element to which prices could be ultimately reduced. Some recent writers have sought a similar role for energy. A lesson, however, of a dual system is that such an element cannot be found in a single economic variable alone. Sraffa's construction of a hypothetical "standard system" which includes only "basic" commodities of the physical system has been regarded as achieving Ricardo's dream of an invariable measure of value (Pasinetti, p. 120, 1978). However, the components of such a standard system cannot be confined to produced commodities and labor. The laws of physics teach us that production cannot take place without the transformation of matter and energy found in the natural environment. Production theory founded on the physical transformations of matter and energy as conceived by the environmental economists is discussed below.

\section{MATERIALS BALANCE AND THE THEORY OF PRODUCTION}

The materials balance approach of the economic-ecological models of Daly, Cumberland (1966), Kneese, Victor, Ayres and others were designed to draw attention of decision makers to the interdependence of economic and environmental systems, in particular, to the fact that economic systems take their inputs from the environment and discharge unwanted products back into the environment. In the main, these models have concentrated on the output side of production-on the problems of predicting and accounting for the residual flows resulting from economic activity. In contrast to traditional economic analysis where residual flows are considered "exceptional," the materials balance approach recognizes the necessity of treating the flows of matter and energy through production (and consumption) activity with the result that the discharge of residuals into the environment is regarded as the inevitable and normal consequence of physical transformations.

Economists using the materials balance approach have been primarily concerned with building operational models of output analysis in order to provide a framework for the policy analysis of pollution. There has been little attempt to consider the full range of environmental inputs, including nonpriced inputs, required in production. Hence the work of the ecologists who have 
modelled energy flows in ecosystems is relevant here (Odum, 1971; Phillipson, 1966; Walters, 1971; and Atkins, 1969). In these models, each taxon (category of organisms) in the ecosystem is viewed as a compartment through which energy passes. The focus of these energy flows is how kilocalories are transformed into a "crop"; primary inputs are the (solar) energy ingested by phytoplankton and considered an "import" in the ecological production system. Attention is given, thereby, to the primary role of inputs in ecological systems.

The theoretical implications of a correct treatment of environmental resources in economic activity becomes apparent in the most recent work of Ayres (1978). As a mathematical physicist, Ayres attacks the neoclassical approach to production theory because of its violation of physical principles. At the same time he describes a theory of physical production consistent with the laws of thermodynamics. This requires, he asserts, a new paradigm of materials-processing activities which is specified at a level of disaggregation that takes into account the variety of differences between resources, materials, forms of energy, and the production processes to which technological changes specifically apply.

The theory of production, neoclassical or otherwise, considers the physical transformation of inputs into outputs and represents technological relationships independent of prices. The neoclassical theory of production has, however, been formulated at a level of abstraction unconcerned with specific sectoral or physical constraints. It begins by assuming that physical output is obtained from the services of resource stocks brought together in a variety of combinations. There is no consideration of the flows of materials or of the nature of specific inputs required in particular processes. Constraints on substitution are given consideration but are applied globally to all inputs. They are not developed from the specific features of input classes. Neoclassical economists, it is obvious, have not started from the physical laws of transformation of inputs into outputs. As a consequence, they have paid insufficient attention to the real constraints of the material and energy combinations found in mechanical, chemical and biological processes.

Starting from the first law of thermodynamics ${ }^{3}$ Ayres sketches a new paradigm based on three broad categories of inputs: Synergistic (complementary), Antagonistic (competitive), and Fixed. The synergistic inputs are those which must be combined in some proportion although the physical proportions may vary. The relation between tractors and gasoline in agriculture is an example of synergy. Neither is of any use without the other, therefore there is no possibility of substitution between them (less gasoline does not increase the need for tractors). Competitive inputs are those where the degree of substitution has no a priori technical limit. Tractors and horses are examples of competitive or antagonistic inputs. ${ }^{4}$ One might replace the other as conditions change just as labor and capital can substitute for each other in many processes. These inputs cannot, however, significantly reduce requirements for materials or energy that become "embodied" in the product. These are "fixed" 
inputs. The application of other factors may eliminate marginal waste but there is a physically determined lower limit of input requirement. Sunlight and water are examples of fixed inputs in agriculture. Per unit of agricultural output, nothing can be substituted for required kilocalories and moisture, although the sources of these may vary.

The transformation of matter and energy into new forms comprises the physical bases of economic activity. While the neoclassical conception of a production function may accord with the facts in some sectors, e.g. in the provision of services, it does not even approximately represent the materials-processing sectors where matter and energy are transformed via technologically specific physical processes. These require particular types of materials, energy, machines and control factors. Machines and energy may substitute for labor and tools; machines or labor can in certain sectors (Ayres mentions lumber and pulp and meatpacking) substantially reduce waste; but neither machines nor labor can reduce the requirements for the materials or energy which become "embodied" in products. ${ }^{5}$ Material inputs cannot, in turn, substitute for capital or labor inputs. These substitutions are, of course, basic to the entire structure of neoclassical theory. Limiting his observations to production theory, Ayres concludes "that neoclassical production functions are basically inappropriate for the materials-processing sectors of the economy" because they "violate thermodynamic principles by implicity permitting labor or capital to 'create' material or energy inputs" (p. 40).

The second law of thermodynamics raises additional difficulties for the traditional theory of production. A generalization of the entropy law implies that high quality natural resources constitute a stock of negentropy (intrinsic order). As these are depleted, the available stock of negentropy is decreased. Low quality natural resources can, of course, be upgraded but this requires the use of energy. Technical advances may increase the efficiency of such processes, but there is always an irreducible minimum energy requirement. A result of this argument is that the faster high quality nonenergy resources are used up the more the demand for (fossil) energy resources will increase. The theory of exhaustible resources, Ayres notes, has not "allowed for the positive feedback between decreasing quality (negentropy) of the remaining resources and the rate of extraction" (Ayres, p.47).

To what extent can technological improvements continue to compensate for the depletion of natural resource (negentropy) stocks? An implication of the second law of thermodynamics is that as nature is transformed into commodities, the immediate and eventual dispersion of natural resources as lowgrade waste back into the environment causes long-run reduction in the productivity and the stability of the natural capital which generates renewable resources. The neoclassical assumption has been that reduced natural productivity and exhaustible resources can be offset by technological improvements. This, as Ayres points out, is tantamount to a denial of the second law for it implies that there is no limit to the amount of negentropy that can be created by intellectual activity (Ayres, p.49). 
Orthodox theory represents economic activity as the optimization of a oneway transformation from original factors of production to goods and services and ultimately to utility and welfare. Physical characteristics of materials and energy transformations are lost in the abstraction to neoclassical production functions. These abstractions, Ayres insists, fail to satisfy even the first law of thermodynamics let alone the deeper laws of physical activity. Ayres therefore introduces a more realistic sequence of mappings: first, from exhaustible or renewable natural resources to finished materials and forms of energy (extraction and conversion processing); second, from materials to material products and structures (manufacturing and fabrication); and, then to abstract services which require resources for their provision. The basic stages of transformation require both environmental resources (matter and energy) and labor, capital goods and intermediate materials. Since these are required in specific physical forms by classifiable mechanical-chemical-biological activities, ${ }^{6}$ Ayres' analysis indicates the necessity of integrating a materials-energy balance emphasis on the flow of material and energy from extraction to waste within an inter-industry flow analysis of the Leontieff-Sraffa type.

\section{IMPLICATIONS OF MATTER AND ENERGY IN ECONOMIC THEORY}

The systematic account of economic activity by classical theorists began in the understanding that economics was the appropriation and transformation of the earth's resources into physical goods. ${ }^{7}$ The first task which classical texts addressed, therefore, was the construction of a theory of production. This was elaborated over the course of the nineteenth century as a theory of 'natural goods' consistent with the physical rules of transformation of materials into new forms. ${ }^{8}$ Economists lacked, however, an adequate framework for treating the implications of physical theory for value and distribution questions.

The neoclassical revolution turned from a concern with physical production to erect a theory of price deriving from the subjective valuation of incremental units of scarce commodities. The theory of production was completed several decades latter (in the 1890's). In analogy to positive but diminishing utility in consumption, positive and diminishing returns were assumed for the separable contributions of each scarce factor stock. The ability to obtain positive increments of output from the successive application of one input to other factors is a version of creatio ex nihilo for it systematically neglects the matter and energy flows required in production. The lack of consistency with physical theory was veiled because of the absence of materials and energy from formal statements of the theory and by the seeming scientific rigor of the mathematical tools employed.

The early neoclassicals attached significant weight to the 'discovery' of the calculus applied to economic theory. Since the appropriate use of mathematics is the concise and powerful expression of an already existing theoretical conceptualization, the important question is not the tools per se, but the validity of 
neoclassical production theory as a representation of processes of physical transformation.

The generalization of the theory of diminishing returns to each factor of production involved an unwarranted departure from classical usage. Formulated from observation of production processes, the classical theory of diminishing returns was applied only to agriculture. It was not regarded as relevant to manufacturing. This distinction arises from the consideration of the technical aspects of production activity. Malthus and Ricardo posit positive and diminishing returns on the extensive margin because successive doses of labor and capital are applied to additional plots, each of diminishing fertility. This provides a clear rationale for diminishing returns. Returns are positive because more land is cultivated but diminishing because land possesses less fertility.

Positive and diminishing returns were assumed for the intensive margin as well but the proposition was not adequately (technically) formulated. Why are returns positive to more intense cultivation of fixed amounts of land? Land area is held constant but its use is not. Inputs (sunlight, nutrients and trace minerals, ground water, carbon dioxide, etc.) which are not included in ordinary production functions are increasing, yet land which is proxy for these is held constant. More output is obtained because more matter and energy are being transformed by the agency of labor and capital employed on the land. The formulation of this problem as a simple partial where land size and use are constant is incorrect.

A neoclassical formulation is

$$
\begin{aligned}
& \mathrm{Q}_{A}=\mathrm{f}(\mathrm{L}, \mathrm{N}, \mathrm{K}) \\
& \left(\frac{\partial^{\mathrm{Q} A}}{\partial(\mathrm{N}-\mathrm{K})}\right)_{\mathrm{L}}=\frac{\partial \mathrm{f}}{\partial(\mathrm{N}-\mathrm{K})}>0
\end{aligned}
$$

i.e., $\mathrm{f}^{\prime}>\mathrm{O}$ and $\mathrm{f}^{\prime \prime}<\mathrm{O}$. $\mathrm{Q}_{\mathrm{A}}$ is agricultural output, $\mathrm{L}, \mathrm{N}$, and $\mathrm{K}$ are land, labor and capital and N-K is a dose of capital and labor.

A more complete representation of technical factors is:

$$
\begin{aligned}
& Q_{A}=f(E, L, N, K) \\
& E=g(L, N, K)
\end{aligned}
$$$$
\partial E / \partial(N-K)>0
$$

where $E$ is the environmental or natural agent requisite to crop production but not provided directly by the farm operator. Since the use of natural agents is governed, in part, by the levels of $\mathrm{N}$ and $\mathrm{K}$ employed, more cultivation enables 
greater absorption of photons, nutrients, water and gases. The chain rule rather than a simple partial applies to this problem:

$$
\left(\frac{\partial Q_{A}}{\partial(N-K)}\right)_{L}=\left(\frac{\partial f}{\partial(N-K)}\right)_{L}+\left(\frac{\partial f}{\partial E}\right)_{L, N, K} \cdot\left(\frac{\partial E}{\partial(N-K)}\right)_{L}
$$

Output is positive if diminishing, in part, because inputs not specified in the neoclassical production function are used in larger quantities. First partials may or may not be positive. The issue is technical rather than economic and it would be incorrect to assume a priori that returns are positive, especially to the successive addition of single classes of inputs.

The classical economists confined diminishing returns to agriculture. Industrial processes were characterized, on the other hand, by constant or increasing returns to scale. This was not a display of an elementary failure to distinguish between returns to a fixed factor and questions of scale. Rather, it was an attempt to represent the propositions (1) that materials derived from the environment to fuel and feed industrial machines were not relatively scarce and could be worked up with the same or increased facility as the scale of production was expanded and (2) that positive but diminishing returns to any single input on a fixed factor had no general technical validity and little sensible application in manufacturing (Senior, 1836, pp. 82-3).

Consider the example of an internal combustion engine. This piece of capital is used to produce the service of power. Engine output $(\mathrm{P})$ plus exhaust (E) is a function of gasoline ( $\mathrm{g}$ ), machine parts $(\mathrm{m})$ and air (a). The gasoline has been refined from crude oil; the machine parts were previously produced from ores, labor, and other machines. Air is an abundant environmental agent required for combustion. The economists's marginal product may be expressed as an increase in gas $(\mathrm{g} \rightarrow \mathrm{g}+\mathrm{dg}$ ) with (a) held constant along with all other inputs:

$$
\frac{\partial(\mathrm{P}+\mathrm{E})}{\partial \mathrm{g}}=\frac{\delta(\mathrm{g}+\mathrm{dg})-\delta(\mathrm{g})}{\mathrm{dg}}>0
$$

This attributes the sole source of increased output to the scarce resource of gas, holding other resource inputs constant. However, if the engine is not permitted to use more air with the gas, the engine will not necessarily produce more output (flooding the engine yields zero output); where $\frac{\partial(\mathrm{P}+\mathrm{E})}{\partial \mathrm{g}} \ngtr 0$. Without considering the contribution of the abundant resource, the value of the "marginal" contribution of gas is meaningless. Gas's marginal value in physical terms is a function of a function.

A specification of matter and energy flows in production activity indicates that a reformulation of the theory of diminishing returns is in order." The 
technical complementarity of energy, raw materials, labor and machine services in production implies that the partial derivative of physical output with respect to any single input cannot be assumed positive a priori. Additions to production from the application of successive increments of a single input are less likely. Attention to the technical aspects of production processes and the nonseparability of input classes in production transformations suggests that neoclassical economists have applied mathematical concepts (the partial) to processes which require a more complex characterization.

The intent of the neoclassical conception of diminishing returns was less a descriptive theory of production than the basis of a theory of distribution. A critique of production theory is, therefore, a critique of the marginal productivity theory of rent applied to all factors of production. This directs attention back to the classical distinction between rent and profit. Rent is determined by the differential productivity of factors limited in supply (land of better qualities, new innovations, workers of exceptional skill, etc.). From a matter and energy perspective, the theory of rent cannot be linked to the marginal productivity of the land by itself but derives from the ability of the land to capture the flow of environmental resources which cycle through the land.

The longer run equilibrium return to reproductive factors (physical capital) in the classical model is not determined in the physical system alone but through its integration with the system of prices. Prices of production include profit paid on the value of capital advanced and distribute the physical surplus of the economic system to each producer. Competition and the entry of capital determine an equilibrium rate of profit across sectors. Since profits in classical theory is that part of physical surplus not distributed as wages and rent, the theory of profit is linked to the question of the source of the surplus.

In contrast to Malthus and others who regarded political economy as an inquiry into the origin of wealth, Ricardo limited his investigation to the laws governing the distribution of wealth. Sraffa follows Ricardo by accepting as exogeneous the physical productivity of the system (the existence of a physical surplus) and does not investigate its source. From the perspective of matter and energy flow, it is clear that the physical surplus (R) in Sraffa's model appears only in the "commodity into commodity" system. A materials balance approach, which accounts for the conservation of matter and energy in the system as a whole, precludes such a surplus. Matter and energy must balance when commodities are produced.

Sraffa's model of the transformation of commodities into commodities was developed as a critique of orthodox economic theory. As a physical representation of production transformations it is incomplete. In particular, it neglects the environmental resources required but not produced in economic activity. Matrix A of equation (1) above must be extended to relate to the taxonomic character of all resource inputs (matter and energy) to their use in production; it must include the non-marketed environmental resources (air, solar kilocalories, assimilative capacity, etc.); it must describe the state of entropy; and it must consider the residuals as well as the accumulation of commodities. 
Once accounted for, the flow of production would not leave a physical commodity surplus. However, the synthesized post-Keynesian-environmentalist system offers insight into the source of the economic (Sraffa) "physical" surplus. The physical surplus only appears within an institutional framework that misconstrues the contributions in production by both the appropriations from nature and the changes in the quality of the state of nature (entropy). Although the unaccounted for agents of nature combine to produce a physical crop, the benefits from this productivity are only realized through the extension of capital. The contributions of the resources that are accounted for in the system are thus assigned a false value in physical terms. The value from the benefits of earth's natural productivity is transferred through the mapping of the physical systems "economic" surplus through the partial accounting system of prices to the owners of the means of production. All those resources which are not "scarce enough" or are incapable of being privately appropriated therefore contribute to the physical surplus and the source of profit.

\section{CONCLUSION}

This paper outlines a new theory of production formed from an integration of the materials-energy balances approach and Post-Keynesian theory which hitherto have stood as isolated attacks on neoclassical theory. Based on the perspective of a theory of production consistent with the transformation of matter and energy into material commodities, this new synthesis suggests a theory of prices formulated according to complete production as well as exchange relations. Distribution theory must be reworked to incorporate the contribution of the natural environment to production. No longer can the core of economic analysis neglect the physical requirements of nature. Until nature's contribution to production is integrated into the foundation of economic analysis, the structure of theory and policy will remain not merely truncated but intellectually and socially misdirected.

FOOTNOTES

1. An open ec.snomy appropriates resolirces outside its domain while a closed economy reproduces itself on its own resources.

2. See Pasinetti, pp. 76-77 (1978).

3. The first law of thermodynamics states that matter and energy are neither created nor destroyed in physical processes. As applied in the materials-energy balance principle this implies that the sum total of materials and energy extracted from the environment as raw materials is exactly equal to the matter and energy returned to the environment as waste flows less capital accumulation and stockpiles.

4. Switching and reswitching between these inputs has been documented by Albin (1975).

5. This insight, which runs counter to neoclassical logic, was advanced by Nassau Senior: "If the labour and the skill now employed throughout England on the manufacture of cotton were doubled, but the quantity of raw

materials remained the same, the quantity of manufactured produce could not be sensibly increased" (Senior, 1836, p. 82).

6. As Ayres indicates (pp. 54-66), consideration of the "methods of chemistry" implies a heterogeneous, sectoral approach to production activity - a classification of uses of materials and of materials by use.

7. La Terre est la source ou la matière d'où l'on tire la Richesse; le travail de l'Homme est la forme qui la produit: \& la Richesse en ellemême, n'est autre chose que la nourriture, les commodites \& les agrémens de la vie." Cantillon (1750), p. 2.

8. Böhm-Bawerk (1891), ch. 1

9. For a brief but penetrating reconsideration of the implications of materials-energy balances for the returns to scale question see Ayres (1978), pp. 40-42. 


\section{REFERENCES}

1. Peter Albin, "Reswitching: An Empirical Observation, Theoretical Note, and an Environmental Conjecture," Kyklos, 1975, 28, pp. 149-153.

2. G. L. Atkins, Multicompartment Models for Biological Systems, (London: Methuen, 1969).

3. Robert Ayres, Resources, Environment, and Economics (New York: John Wiley and Sons, 1978).

4. Consumption \& Externalities," The American Economics Review LIX, June 1969, pp. 282-97.

5. Eugen von Böhm-Bawerk (1891), The Positive Theory of Capital, (New York: G. E. Stechert, 1923).

6. Richard Cantillon (1750), Essai Sur la Nature du Commerce en Général, (London: Macmillan, 1931).

7. J. H. Cumberland, "A Regional Inter-Industry Model for Analysis of Development Objectives," Regional Science Association Papers, 17, 1966, pp. 65-95.

8. H. E. Daly, "On Economics as a Life Science," Journal of Political Economy, May/June 1968.

9. G. C. Harcourt, "The Cambridge Controversies: Old Ways and New Horizons-or Dead End?" Oxford Economic Papers, Vol. 28, March 1976, pp. 25-55.

10. O. C. Herfindahl and A. V. Kneese, Economic Theory of Natural Resources, (Columbus, Ohio: Merril, 1974)

11. Walter Isard, "On the Linkage of Socioeconomic and Ecological Systems," Papers of the Regional Science Association, Vol. 21, 1978.
12. Nicholas Kaldor, "A Model of Economic Growth," Economic Journal, 1957, pp. 591-624.

13. D. Laibman and E. J. Nell, "Reswitching, Wicksell Effects, and the Neoclassical Production Function," American Economic Review, Vol. 67 (5) December 1977, pp. 878-88.

14. Wassily Leontief, The Structure of American Economy 1919-1929, (Cambridge, Mass: Harvard University Press, 1971).

15. E. P. Odum, Environment, Power and Society, (New York: Wiley Interscience, 1971).

16. Luigi Pasinetti, Lectures on the Theory of Production, (New York: Columbia University Press, 1977).

17. J. Phillipson, Ecological Energetics, (London: Arnold, 1966).

18. David Ricardo, On the Principles of Political Economy and Taxation (1821), vol. 1 of The Works and Correspondence of David Ricardo, ed. P. Sraffa (Cambridge: Cambridge University Press, 1951).

19. Nassau Senior (1836), An Outline of the Science of Political Economy, New York: A. M. Kelley, 1965).

20. Piero Sraffa, Production of Commodities by Means of Commodities, (Cambridge: Cambridge University Press, 1960).

21. Peter A. Victor, Pollution: Economy and Environment, (Toronto, Canada: University of Toronto Press, 1972).

22. C. J. Walters, "Systems Ecology: The Systems Approach and Mathematical Models in Ecology," in E. P. Odum (ed.), Fundamentals of Ecology, (Philadelphia: W. Saunders, $1971)$. 